\title{
Mercado da nostalgia e narrativas audiovisuais
}

\author{
Ana Paula Goulart Ribeiro
}

\section{Resumo}

0 mercado da nostalgia caracteriza-se pela comercialização de objetos e narrativas que, de uma forma emocional e afetiva, remetem ao passado, seja como referência histórica e cultural, como espaço de experiência, seja como modelo estético. Partindo dessa definição, propomo-nos a refletir sobre 0 apelo nostálgico de algumas produções televisivas e cinematográficas e sobre seus significados. Acreditamos que a nostalgia contemporânea pode expressar uma visão romântica ou conservadora do passado, mas pode também ser marcada por potências e positividades. A nostalgia diz muito sobre a forma ambígua e contraditória com que nos relacionamos hoje com nossa temporalidade.

\section{Palavras-Chave}

Memória. Nostalgia. Temporalidade

\section{Introdução}

Diversas são as práticas mnemônicas que conformam a cultura da memória no mundo contemporâneo. Minha proposta é investigar um aspecto específico dessa cultura, a que podemos chamar de "mercado da nostalgia". Esse mercado caracteriza-se pela comercialização de objetos e narrativas que, de uma forma emocional e afetiva, remetem ao passado, seja como referência histórica e cultural, como espaço de experiência, seja apenas como modelo estético.

0 mercado da nostalgia engloba nichos os mais variados. Está presente em todo o tipo de indústria do consumo: na arquitetura, no vestuário, na decoração, em brinquedos, em games, no design de móveis e joias, na música, em bares e restaurantes e em diversas formas de entretenimento, como parques de diversão, festas e performances ${ }^{1}$.

A nostalgia, como objeto de consumo, parece onipresente, mas é nas mídias que ocupa um lugar de destaque. 0 culto nostálgico do passado
Ana Paula Goulart Ribeiro

Doutora em Comunicação e Cultura - Universidade Federal do Rio de Janeiro (UFRJ), professora da UFRJ, Rio de Janeiro, Rio de Janeiro, Brasil. E-mail: goulartap@gmail.com https://orcid.org/0000-0002-9341-4629 
perpassa a sociedade como um todo, inclusive as práticas pessoais mais cotidianas, como 0 desejo de tudo guardar, colecionar e arquivar. No entanto, é nos meios de comunicação que ele ganha maior visibilidade e poder de agenciamento social. Parecer haver uma intrínseca relação entre nostalgia, cultura da memória e cultura da mídia. É esse argumento que gostaria de desenvolver, na busca de tentar entender como a memória e a nostalgia, através da mídia (sobretudo a audiovisual), constroem identidades sociais e processos de subjetivação.

\section{Afinal, o que entendemos por nostalgia?}

Nem toda referência ao passado é necessariamente nostálgica. Mas o que distingue a nostalgia de outros usos do passado e de outras práticas mnemônicas? 0 vocábulo nostalgia foi usado pela primeira vez na Europa no século XVII, para se referir à patologia provocada pelo "desejo de voltar para casa". Naquele momento, a mobilidade espacial ainda era restrita, e o ritmo cadenciado do tempo era rompido apenas por eventos extraordinários, como guerras e catástrofes naturais. 0 afastamento da terra natal era uma anomalia e provocava em muitos um estado disruptivo ${ }^{2}$. Mas a modernidade mudou isso.

Quando o tempo começou a se acelerar, criando profundas descontinuidades na vida, a nostalgia deixou de ser um problema de apenas algumas poucas pessoas deslocadas. A consciênciada mudança inexorável, da transitoriedade da existência (FREUD, 1989), expandiu-se e levou muitas pessoas a desejar seus lugares e tempos perdidos. A modernidade valorizou o novo e a ruptura com a tradição, mas produziu também desejo de conter a história, recusa à irreversibilidade do tempo. Talvez uma das imagens mais bonitas sobre esse sentimento seja a do Anjo da História, do Walter Benjamin (1985). 0 anjo tem seu olhar voltado para o passado e, sob seus pés, se acumulam ruínas sobre ruínas. Ele queria parar, acordar os mortos e recompor 0 destruído, mas é empurrado para frente por uma tempestade, a que Benjamim chama de progresso.

A nostalgia é entendida, nesse caso, como uma relação problemática que indivíduos, grupos e sociedades estabelecem com a tempo linear e direcionado ao progresso, tal como configurado pela tradição iluminista. A nostalgia seria um tipo particular de prática mnemônica, na qual temporalidade é tensionada por um movimento

Sobre memória e performance, ver o trabalho de Mônica Ferrari Nunes (2015). A autora estuda formas de expressão juvenis, como os cosplay.

Criado em 1688 pelo médico Johannes Hofer, o termo nostalgia foi usado como diagnóstico de muitos soldados e marinheiros afastados de suas terras natais durante várias guerras do século XVIII. Seus sintomas eram febre, insônia, taquicardia, falta de apetite e declínio das forças. No início do XIX, já tinha se generalizado como um mal que poderia acometer indivíduos de qualquer profissão, grupo étnico ou nacionalidade. Sobre a história do termo, ver DAVIS (1979), NATALI (2006), CROSS (2015) e SPRENGLER (2011). 
que tende a valorizar o passado em detrimento do futuro (RIBEIR0 e MADUEL, 2017). Não se trata, portanto, de uma novidade da atualidade. Podemos pensar que é mesmo um fenômeno próprio do ser moderno. Já no século XVII, a nostalgia foi uma dimensão importante do romantismo, em sua reação e resistência à modernização capitalista. Ali o passado apresentava-se não como algo a se superar, mas como uma falta. Era pensado não como arcaico, mas um autêntico lugar de retorno de valores morais, políticos ou estéticos.

Mas será que o conceito de nostalgia, nessa sua acepção moderna, aplica-se aos fenômenos que pretendemos estudar? Sem dúvida, o consumo desenfreado de narrativas e artefatos do passado representa 0 desejo de trazer, para o presente, elementos de um tempo pretérito. No entanto, parece haver algo a mais no apelo ao nostálgico que fazemos hoje, sobretudo no mercado de bens culturais. Parece que, nas últimas décadas, novas sensibilidades em relação ao passado e formas peculiares de acionar nossas experiências pretéritas foram desenvolvidas. E são as dinâmicas (os modos de funcionamento) e os sentidos dessa forma peculiar de memória que gostaríamos de compreender.

\section{Há diferentes entendimentos e mesmo} divergências em relação ao conceito de nostalgia, sobretudo entre a primeira geração de autores que, nos anos 1980 e 1990, estudou o tema na relação com cultura da mídia (DAVIS, 1979; JAMESON, 1991; HUTCHEON, 1998), e os autores contemporâneos que, na última década, têm desenvolvido pesquisas sobre 0 assunto (NIERMEYER, 2011; HOLDSWORTH, 2011; SPRENGLER, 2001; CROSS, 2015; BEAIL e GOREN, 2015). Minha reflexão - mais sintonizada com a segunda geração de pensadores - parte da ideia de que 0 gesto nostálgico pode adquirir sentidos variados e até mesmo opostos nos produtos da cultura midiática. Pode-se fazer de uma forma romântica e pouco problematizadora, mas também com uma intenção crítica, não só em relação ao passado propriamente dito, mas ao que dele permanece no presente. Pode-se exprimir melancolia e saudosismo, mas também positividade e alegria. Pode representar alienação e escapismo, mas também pode proporcionar uma experiência rica e reflexiva. Pode se esgotar na imediatez do consumo ou sedimentar algum tipo de conhecimento.

Uma característica, no entanto, que parece marcante do mercado de nostalgia em geral é a forma fragmentada com que o passado é apropriado. Muitas vezes, faz-se referência apenas a alguns de seus símbolos e ícones, de forma isolada e descontextualizada. Nesses casos, o passado é acionado de forma alusiva, como elemento de produção de familiaridade, conexão emocional e identificação do consumidor com os produtos.

Outra questão é que, algumas vezes, os produtos nostálgicos voltam-se para um passado glorioso, de grandes feitos e personalidades (como 0 
cinema hollywoodiano e boa parte da ficção televisiva brasileira). Mas, em outras, apelam para a memória do trivial, comezinho, cotidiano, banal (como as músicas antigas tocadas nas rádios, filmes e séries reprisados em canais por assinaturas). No segundo caso, o que está em jogo é a nostalgia pelo que foi vivido e experimentado por nós em nossa infância e juventude.

Trata-se um tipo específico de apego ao passado, que Gary Cross (2015) chama de "consumed nostalgia" e que ele identifica como característica do capitalismo tardio. Imagens, sons, cheiros e sabores evocam memórias pessoais e desejo de reviver sensorialidades e emoções de outrora, ligadas, elas mesmas, a formas de consumo dos anos de formação dos indivíduos. Esse fenômeno nos diz muito sobre as experiências dos adultos e idosos de hoje. Nossa cultura valoriza a potência da juventude e 0 porvir da criança - 0 que torna a infância e a juventude idades de ouro, que adultos e idosos desejam resgatar.

Mas a questão é mais difícil de explicar quando pensamos na cultura juvenil, também ela fortemente impregnada de elementos nostálgicos. Por que jovens se interessam por produtos de um passado que eles não conheceram? Por que se interessam por histórias consumidas por seus pais e avós? Será possível, nesse caso, falar em uma nostalgia do que não se viveu? Se sim, de que se nutre esse sentimento?

\section{Temas históricos, reprises e reconstituições de época}

A estreita relação entre nostalgia e cultura da mídia pode ser observada em diferentes produtos audiovisuais contemporâneos. As superproduções cinematográficas com temática histórica, assim como inúmeras séries exibidas na televisão ou em canais em streaming são um exemplo disso. Há canais dedicados integralmente à história, assim como existem programas voltados para 0 passado $0^{3} \mathrm{e}$, mesmo, canais de reprises, como o Canal Viva, da programadora de TV por assinatura Globosat ${ }^{4}$. Na mesma linha de apelo à memória afetiva e à nostalgia do telespectador, pode-se citar 0 Vale a Pena Ver de Novo, faixa da programação vespertina da Globo, que, desde 1980, reexibe novelas de sucesso da própria emissora. Sua longa duração - quase 40 anos - demonstra a boa receptividade desse tipo de iniciativa.

Arquivo N, exibido pela GloboNews, é um exemplo. 0 programa propõe ao telespectador uma "viagem no tempo" e, para isso, realiza trabalho de pesquisa sobre fatos e pessoas que marcaram a história. Traz imagens do acervo da TV Globo e de outras emissoras, áudios de rádios, manchetes antigas de jornais e depoimentos de pessoas que foram testemunhas de fatos do passado considerados relevantes.

Desde a sua estreia, em 2010, 0 canal dedica grande parte da sua programação a reprises de programas antigos da TV Globo. 0 Viva também reprisa séries estrangeiras de grande sucesso, como Dallas e Twin Peaks. E investe em produções próprias. Em maio de 2016, por exemplo, começou a exibir uma nova versão de TV Mulher, grande sucesso dos 1980. 0 programa atual é comandado pela mesma apresentadora que conduzia 0 antigo, a jornalista Marília Gabriela. 
As reprises são fundamentais na programação da maioria das TVs por assinatura. Algumas reexibem programas relativamente recentes apenas para conseguir preencher sua grade. Mas outras procuram mesmo investir no desejo nostálgico do telespectador. Assim, toda uma geração que cresceu assistindo à TV nos anos 1970 e 1980 pode rever as séries preferidas de sua infância e adolescência ${ }^{5}$. Para deleite de alguns fãs, essas séries são muitas vezes também comercializadas em DVD.

No caso da teledramaturgia brasileira, sua relação com o passado é antiga. Desde os seus primórdios, na metade do século XX, a ficção televisiva explorou temas históricos e reconstituições de época. Mas não deixam de chamar atenção as produções que, nos últimos anos, exploram essa dimensão com uma ênfase sistemática, sobretudo em minisséries. 0 tema aparece associado não apenas à ficcionalidade, mas também aos chamados "fatos e personagens reais". A TV Globo produz, em geral, duas minisséries por ano e, de 2003 a 2014, pelo menos uma foi sempre dedicada a um tema histórico ou biográfico ${ }^{6}$.

0 mercado audiovisual da nostalgia aposta muito também em reconstituições de época. São produções que não se referenciam necessariamente a acontecimentos e personagens reais, mas que criam universos ficcionais ambientados em tempo idos. Entre as séries americanas de sucesso que procuram reconstituir a atmosfera de outras épocas, destaca-se Stranger Things, distribuída pela Netflix desde 2016. Trata-se de uma cuidadosa reconstituição dos anos 1980, com figurino, cenografia e caracterização ricos em detalhes. A série, criada por Matt e Ross Duffer, conta como familiares e amigos lidam com o misterioso desaparecimento de um menino numa pacata cidade dos Estados Unidos. A linguagem não poderia ser mais pós-moderna: trata-se de uma colagem de referências - às vezes sutis, às vezes explícitas - de séries e filmes como Contatos Imediatos do Terceiro Grau (1977), Alien, o oitavo passageiro (1979), O Iluminado (1980), Poltergeist (1982), ET, o extraterrestre (1982), De Volta para o Futuro (1985) e Arquivo X (1993).

A própria trama baseia-se num certo imaginário de época construído por esses produtos audiovisuais: teorias conspiratórias envolvendo 0 governo americano, extraterrestres, experimentos científicos, sobrenatural. A centralidade da narrativa no elenco infantil é um dos elementos que também ajuda a produzir uma sensação de familiaridade, reconfortante para quem 
viveu aquela época ou para quem consumiu os produtos culturais do período. Os irmãos Duffer misturaram todo o tipo de influência e buscaram, como eles mesmo disseram, trazer de volta a "sensibilidade" do passado.

Mad Men (2007-2011) é outro exemplo de produto nostálgico. A série - exibida no Brasil pela HBO é ambientada nos anos 1950 e 1960, período-chave da história norte-americana. A prosperidade econômica do pós-Guerra, o crescimento da classe média e a emergência da Guerra Fria criaram a moderna identidade dos EUA, como argumentam Linda Beail e Lilly Goren (2015). Nesse período, a nação foi "refundada" como uma superpotência militar e econômica. As noções de mobilidade social e sonho americano foram moldadas. Foi quando se criou uma América mais próspera, anticomunista e imperial, mas também quando houve 0 "fim da inocência americana", com a revolução sexual, as lutas raciais, a Guerra do Vietnã e os assassinatos de JFK e Luther King, entre outros eventos.

É nesse ambiente que vive Don Drapper (Jon Hamm), diretor de criação de uma agência de publicidade de Nova York. Sua vida profissional e pessoal, assim como a de outras pessoas com quem trabalha, são o foco da trama de Mad Men. 0 criador da série, Matthew Weiner, a descreveu como de ficção científica, só que voltada para o passado. Segundo ele, o programa usa os anos 1950 e 1960 para discutir questões ainda presentes de forma velada na sociedade americana. A ideia do autor é de que história pode iluminar nossos dilemas políticos atuais.

0 trabalho de reconstituição de época da série é extremamente cuidadoso, tanto em termos de cenografia, figurino e caracterização, quanto na construção da trama e redação dos diálogos. Apresentando um retrato realista do sexismo e do racismo dos anos 1950 e 1960, a série choca os expectadores contemporâneos ao mostrar a aparente distância entre 0 que era naturalizado na época e o que hoje não é esperado como comportamento padrão (ou "politicamente correto").

0 risco, como mais uma vez argumentam Beail e Goren (2015), é não se perceber a intenção crítica do autor e imaginar o quanto nossas vidas são melhores, mais razoáveis e sensíveis do que a daquele tempo. Mad Men apela por uma espécie de nostalgia ao contrário: ao invés de idealizado como melhor, o passado é visto criticamente. A série permite que nos sintamos superiores aos "velhos maus tempos", quando chefes dormiam com suas secretarias, mulheres fumavam e bebiam durante a gravidez, e famílias deixavam casualmente todo o seu lixo no parque depois do piquenique (cena antológica que fecha um dos episódios da primeira temporada da série). Além disso, Mad Men apresenta um paradoxo político. Don Draper e seus colegas estavam inventando o mundo do consumo. E se, por um lado, a série critica a publicidade como produtora de desejos artificiais, por outro, contribui para um marketing amplo e para o próprio consumo. A Banana 
Republic, por exemplo, criou uma edição limitada de roupas e acessórios inspirados no figurino dos personagens (CROSS, 2015).

A série Gothan - criada por Bruno Heller e transmitida no Brasil pela Warner e pela Netflix desde 2014 - é uma espécie de prequela da história de Batman e se caracteriza por uma nostalgia de tipo diferente. Não se trata de uma reprise, um remake ou uma reconstituição de época tout court. Mas de uma produção que busca 0 antecedente de uma experiência pretérita qualquer, nem idealizada como melhor e nem criticada como pior. A referência ao passado, além disso, é de um tipo muito particular, pois não remete a uma época definida cronologicamente. Há uma cena, nesse sentido, bastante emblemática. 0 futuro comissário Gordon dá uma entrevista coletiva; em torno dele, encontram-se muitos repórteres e fotógrafos. Há uma mistura de referências temporais diversas nas câmeras e os outros equipamentos que os profissionais trazem em mãos: são máquinas fotográficas de diferentes décadas, de antigas rolleiflex a câmeras digitais.

Game of Thrones, exibida desde 2011 pela HB0, faz algo similar. A série - criada por David Benioff e D. B. Weiss, a partir da obra de
George R. R. Martin - é ambientada num tempo indefinido, mítico. Mas faz inúmeras alusões à Idade Média nos figurinos e nas caracterizações, assim como na própria trama, apesar de seu apelo ao universo fantástico dos zumbis. A referência ao passado na série chama atenção e já foi amplamente discutida em reportagens, sites e redes sociais. 0 próprio George R. R. Martin falou sobre a inspiração histórica do programa e se declarou colecionador de cavaleiros medievais em miniatura.

\section{Remakes e reboots, prequelas e sequelas}

Um mecanismo comum da cultura da memória e da nostalgia é o da produção de remakes.

No Brasil, esse fenômeno é especialmente significativo na televisão. Desde o início dos anos 2000, só a Globo produziu mais de uma dezena de remakes de sucessos dos anos 1970 e $1980^{7}$. 0 cinema, sobretudo o hollywoodiano, também tem investido maciçamente na remontagem de antigos clássicos. 0 interessante nesses casos e no das reprises é que se trata de um fenômeno da cultura da memória à medida que é um relembrar, um rever nostálgico para as antigas gerações. Mas se trata também de um fenômeno "novo", uma vez que esse material nunca foi visto

Seguem o título das remakes, com as datas da primeira e da segunda versões: Cabocla (1979/2004), Sinhá Moça (1986/2006), Ciranda de Pedra (1981/2008), Paraíso (1982/2009), Ti-Ti-Ti (1985/2010), 0 Astro (1977/2011), O Bem-Amado (1973/2011), Gabriela (1975/2012), Guerra dos Sexos (1983/2012), Saramandaia (1976/2013) e Rebu (1974-2014). Em 2016, a emissora exibiu também a novela Haja Coração, uma releitura de Sassaricando (1987). 
pelas pessoas mais jovens, muitas delas sequer nascidas na época da exibição da primeira edição dos filmes ou programas televisivos.

É preciso, no entanto, ser cuidado na qualificação desse "novo", que propositadamente foi usado entre aspas. Mesmo para aqueles que assistem a esse material pela primeira vez, não se trata de algo de fato inédito. Todos sabem que estão vendo regravações ou releituras de produtos culturais do passado, e esse fato é, inclusive, fartamente alardeado pelos produtores. É usado como um elemento de distinção dos programas, importante nas campanhas de lançamento dos produtos. É preciso considerar também um outro aspecto: há alterações importantes no consumo e na fruição desses produtos. No caso das novelas brasileiras, por exemplo, os telespectadores já têm informações prévias sobre as histórias e os personagens e buscam se informar antecipadamente sobre o desenrolar da trama. Além disso, é ativada a curiosidade comparativa, que faz com que as pessoas procurem dados sobre enredos, personagens e atores das primeiras versões. Para isso, o público dispõe de inúmeros sites e blogs dedicados à ficção televisiva e sua história. A própria TV Globo tem um portal - o Memória Globo $^{8}$ - no qual o telespectador pode encontrar informações detalhadas, fotografias e vídeos sobre todas as produções da emissora (ligadas ao entretenimento, jornalismo e esporte) desde sua inauguração, em 1965, até os dias atuais.

Uma prática usual no cinema de nostalgia é a produção de prequela (obra que é ambientada no mesmo universo ficcional de uma outra, mas cuja história lhe antecede) e sequela (cuja história lhe sucede). A prequela, em geral, explica o passado que levou os eventos da narrativa original acontecer, e a sequela conta os desdobramentos da história. Um clássico do cinema a investir nesse nicho foi Star War. Criado por George Lucas, o filme foi lançado em 1977 e, rapidamente, tornou-se um dos maiores sucessos de bilheteria de todos os tempos. Logo foi seguido por dois outros filmes: O Império contra-ataca (1980) e $O$ retorno de Jedi (1983), ambos também com grande repercussão. Anos depois, apareceu a trilogia de prequela: Star War Episódio I: A ameaça fantasma (1999), Ataque dos Clones (2002) e Vingança de Sith (2005). Essa segunda série, que contava as origens do vilão Darth Vader, fez sucesso, mas não encantou o público como as películas iniciais.

Em 2015, no entanto, foi lançado o primeiro filme de uma terceira trilogia, o Despertar da Força, uma sequela. Foi um fenômeno, a maior bilheteria de estreia da história do cinema. Trinta e oito anos depois do primeiro Star War, a epopeia se revitalizou. Desta vez, houve investimento 
em elementos novos, mas apostou-se pesado na nostalgia. Com destreza, foi produzida uma sensação de familiaridade pelo uso de figurino e elementos cenográficos com muitas referências ao filme original. E 0 antigo elenco foi trazido de volta. 0 aparecimento do envelhecido Hans Solon (Harrison Ford) - após minutos de filme - emocionou o público, assim como a cena em que ele se encontra com a Princesa Léa (Carrie Fisher ${ }^{9}$ ). No final, um imponente Luke Sky Walker (Mark Hamil) promete novas emoções para o próximo episódio. No meio de tudo, há a presença simpática - de grande apelo nostálgico - do Chewbacca e dos robôs CP03 e R2D2.

É interessante observar que, em 2008, poucos anos antes do Despertar da Força, Harrison Ford tinha participado da sequela de outra trilogia de grande sucesso, também criado por George Lucas três décadas antes. Em Indiana Jones e o Reino da Caveira de Cristal, o ator reviveu - ao lado da atriz Karen Allen - 0 carismático arqueólogo dos filmes Caçadores da Arca Perdida (1981), Indiana Jones e o Templo da Perdição (1984) e Indiana Jones e a Última Cruzada (1989). Em 2017, Ford revive mais um de seus personagens de sucesso. Rick Deckard, o caçador de androides, volta às telas em Blade Runner 2049, sequela do cultuado Blade Runner, filme de ficção científica dirigido por Ridley Scott nos anos 1980. A notícia sobre o lançamento do novo filme, dirigido por
Denis Villeneuve, gerou grandes expectativas entre fãs e críticos de cinema.

Um dado curioso é que nem mesmo os filmes infantis ficam imunes ao boom nostálgico. 0 longa de animação Minions (2015), prequela de $M e u$ Malvado Favorito (2010), é um exemplo disso. Em 1968, na busca de um vilão para servirem, Kelvin, Stuart e Bob chegam a Nova York. Logo se deparam com um cartaz de propaganda de Richard Nixon à presidência, uma passeata pacifista liderada por alguns hippies e carros psicodélicos. Quando chegam à Inglaterra, eles encontram a jovem rainha Elizabeth e a Londres dos anos 1960. A trilha sonora do filme não podia ser mais nostálgica: Jimi Hendrix (Foxy Lady), The Doors (Break on Thought to the Other Side) e The Turtles (Happy Together).

São muitas as referências ao passado na ambientação da história dos Minions, mas por que um filme voltado ao público infantil investe em nostalgia dessa forma? Por que fazer tantas referências a um tempo que esse público não viveu e a elementos em relação aos quais a maior parte não se identifica diretamente? Ora, como qualquer produto cultural, Minions apresenta várias camadas de leitura possíveis. Entrecruza textos diversos, que permitem variados níveis de compreensão e apropriação. 0 filme explora as possibilidades do interdiscurso e constrói 
uma narrativa que pode ser agradavelmente consumida por diferentes faixas etárias.

Outros longas infantis têm feito o mesmo. Animações como Shrek (2001), Era do Gelo (2002), Espanta Tubarões (2004) e Madagascar (2005) trazem referências a psicodelismo, uso de drogas, homossexualidade e vários outros assuntos "não infantis". Há piadas dirigidas aos pais ou a outro adulto que se anime a assistir a tais filmes. A tarefa de acompanhar as crianças se torna, assim, mais prazerosa ou menos árdua. É o que acontece também com Trolls (2016), animação produzida pela DreamWorks. Repleto de referências nostálgicas, o filme tem seu ponto alto na animada trilha sonora, produzida por Justin Timberlake, que recria clássicos da música pop dos anos 1960 a 1980, como The sound of silence (Simon \& Garfunkel), September (Earth, Wind \& Fire), True collors (Cyndi Lauper), Hello (Lionel Richie), Total eclipse of the heart (Bonnie Tyler) e Celebration (Kool e the Gang).

Outro filme infantil de grande apelo nostálgico é Toy Story. A memória das brincadeiras de criança foi o combustível usado pela Pixar para lançar seu primeiro longa metragem em 1995. É uma história sobre brinquedos, contada pela perspectiva dos próprios brinquedos. Nesse universo, destacam-se 0 cowboy Woody e 0 astronauta Buzz Lightyear, bonecos do menino Andy. 0 filme teve uma continuação em 1999 e outra em 2010. 0 intervalo de tempo real e diegético entre o segundo e 0 terceiro filme foi de 11 anos. Nesse período, Andy cresceu, assim como os expectadores dos dois primeiros filmes. Ele tem, agora, 17 anos e está prestes a ir para faculdade. Precisa arrumar 0 quarto e definir o que fazer com seus antigos brinquedos. Toy Story 3 tem um ponto de partida melancólico. É um filme sobre a passagem do tempo e a transitoriedade da vida.

\section{De que se nutre a nostalgia?}

No mercado da nostalgia há, obviamente, uma dimensão econômica essencial. 0 passado - sobretudo através de seu apelo emocional vende muito. Mobiliza de tal forma a economia de bens materiais e simbólicos de diversos países que é mesmo difícil de mensurar. Tem características locais e nacionais, mas é também um fenômeno transnacional e mundializado. A pujança econômica do mercado da nostalgia, no entanto, não é central em nossa reflexão. A questão nos interessa apenas na medida em que remete para algo além dela mesma.

É como fenômeno cultural (no sentido mais amplo que esse termo pode assumir) que 0 assunto nos instiga. A obsessão pela nostalgia é um sintoma de algo que está para além dela e que gostaríamos de entender.

Estamos falando de uma forma específica de experimentar o tempo que diz muito do que somos, como vivemos e como significamos a nós mesmos e ao mundo ao nosso redor. 0 apego e a valorização do passado não é um fenômeno novo, como vimos, mas o boom nostálgico das últimas 
décadas traz elementos singulares, que são muito significativos para entendermos nossa cultura e as maneiras de dinamizarmos nossas identidades ou identificações. Por que nos voltamos para 0 passado? Quais são as experiências pretéritas que valorizamos e quais são as que ignoramos? Por que lembramos o que lembramos? Como lembramos? Por que 0 fazemos de tal forma e não de muitas outras possíveis? A que exatamente a nostalgia apela? Por que seus produtos nos atraem tanto?

Uma dimensão da questão nos parece clara. A nostalgia está relacionada à dificuldade que temos de lidar com nossa própria temporalidade. Sua lógica essencial parece fácil de entender. Num cenário caracterizado por vínculos sociais e afetivos mais frágeis e provisórios, pela descrença nas grandes narrativas explicadoras do mundo e nos projetos políticos transformadores, 0 desejo de passado expressa o esfacelamento de nossa capacidade de projeção, nossa dificuldade de imaginar "futuros possíveis" (HUYSSEN, 2014).

A nostalgia contemporânea, entretanto, parece expressar também nossa consciência da ação implacável e destruidora do tempo. Há algo de necrófilo em seu gesto, que busca ignorar mortes e perdas e que procura resistir à velocidade das mudanças, à rapidez e ao efêmero. Expressa, portanto, mais do que a falência de futuro. Expressa nossa dificuldade de viver e dar sentidos a nosso presente, que alguns consideram expandido (HARTOG, 2013), mas que, em nossa experiência, parece excessivamente contraído, sem espessura, difícil de sentir. Por outro lado, o passado que consumimos não é mais igual ao que era antigamente. A história deixou de funcionar como magistra vitae, fomentadora de ações e projetos. Não conseguimos mais ver "no que se foi" algo que dê sentido ao que somos, e parece que nem sabemos exatamente 0 que queremos ou poderemos ser.

0 nosso "mal-estar" de estar no tempo reflete-se, portanto, na nostalgia, seja naquela que apela aos grandes personagens e momentos da história, seja na que retoma o banal, a experiência cotidiana, as sensações por nós mesmos vividas em nossa infância ou juventude, seja ainda na que busca remontar a ambiência de gerações passadas. Mas que respostas essas diferentes formas de nostalgia são capazes de produzir para esse sentimento de "desconforto temporal"? Acreditamos que podem ser múltiplas e variadas, e que cabe ao pesquisador da comunicação e da cultura tentar entendê-las. Aqui, apenas iniciamos nosso percurso investigativo.

\section{Referências}

BEAIL, Linda e GOREN, Lilly J. Mad Men and politics: nostalgia and the remaking of modern America. New York/London: Bloomsbury, 2015. BENJAMIN, Walter. Origem do drama barroco alemão. São Paulo: Brasiliense, 1984.

CROSS, Gary. Consumed nostalgia: memory in the age of fast capitalism. New York: Columbia University Press, 2015. 
DAVIS, Fred. Yearning for yesterday: a sociology of nostalgia. New York: Free Press, 1979.

FREUD, Sigmund. "Sobre a Transitoriedade". In Jornal do Brasil, 23/09/1989.

HARTOG, François. Regimes de historicidade: presentismo e experiência do tempo. Belo Horizonte: Autêntica, 2013.

HOLDSWORTH, Amy. Television, memory and nostalgia. Palgrave Macmillan, 2011.

HUYSSEN, Andreas. Seduzidos pela memória. Rio de Janeiro: Aeroplano Editora, Universidade Cândido Mendes, Museu de Arte Moderna-RJ, 2000.

\section{Culturas do passado-presente;}

modernismos, artes visuais, políticas da memória. Rio de Janeiro, Contraponto, 2014.

HUTCHEON, Linda. "Irony, Nostalgia, and the Postmodern”. University of Toronto English Language (UTEL) Main Collection, 1998.

JAMESON, Fredric. "Nostagia for the presente". In. Postmodernism, or the cultural logic of late capitalism. Durkham, Duke University Press, 1991.

NATALI, Marcos Piason. A política da nostalgia: um estudo das formas do passado. São Paulo: Nankin, 2006.

NIEMEYER, Katharina. Media and Nostalgia: yearning for the past, presente and future. Palgrave Macmillan.

NUNES, Mônica Rebecca Ferrari (org.). Cena cosplay: comunicação, consumo, memória nas culturas juvenis. Porto Alegre: Sulina, 2015.

RIBEIRO, Ana Paula Goulart e MADUEL, Itala. "0 Jornal do Brasil é que era jornal de verdade: jornalismo, memórias e nostalgia". Texto apresentado no $26^{\circ}$ encontro nacional da Compós, São Paulo, 2017.

SPLENGER, Christine. Screening Nostalgia: populuxe props and technicolor aesthetics in contemporary american film. Berghaln Books, 2011. 


\begin{tabular}{|c|c|}
\hline $\begin{array}{l}\text { Nostalgia Market and } \\
\text { audiovisual narratives }\end{array}$ & $\begin{array}{l}\text { Mercado de la nostalgia } \\
\text { y narrativas audiovisuales }\end{array}$ \\
\hline $\begin{array}{l}\text { Abstract } \\
\text { The nostalgia market is characterized by the } \\
\text { commercialization of objects and narratives that, } \\
\text { in an emotional and affective way, refer back to the } \\
\text { past, either as a historical and cultural reference, } \\
\text { as a space of experience or as an aesthetic model. } \\
\text { Starting from this definition, we propose to reflect } \\
\text { on the nostalgic appeal of some television and } \\
\text { cinematographic productions and its meanings. } \\
\text { We believe that contemporary nostalgia can express } \\
\text { a romantic or conservative view of the past, but } \\
\text { it can also be marked by potencies and positivities. } \\
\text { Nostalgia says a lot about the ambiguous and } \\
\text { contradictory way in which we relate today to } \\
\text { our temporality. } \\
\text { Keywords } \\
\text { Memory. Nostalgia. Temporality. }\end{array}$ & $\begin{array}{l}\text { Resumen } \\
\text { El mercado de la nostalgia se caracteriza por la } \\
\text { comercialización de objetos y narrativas que, de una } \\
\text { forma emocional y afectiva, remiten al pasado, sea } \\
\text { como referencia histórica y cultural, como espacio } \\
\text { de experiencia o como modelo estético. A partir de } \\
\text { esta definición, nos proponemos reflexionar sobre el } \\
\text { atractivo nostálgico de algunas producciones televisivas } \\
\text { y cinematográficas y sobre sus significados. Creemos } \\
\text { que la nostalgia contemporánea puede expresar } \\
\text { una visión romántica o conservadora del pasado, } \\
\text { pero también puede ser marcada por potencias y } \\
\text { positividades. La nostalgia dice mucho sobre la forma } \\
\text { ambigua y contradictoria con que nos relacionamos } \\
\text { hoy con nuestra temporalidad. } \\
\text { Palabras-clave } \\
\text { La memoria. Nostalgia. Temporalidad. }\end{array}$ \\
\hline
\end{tabular}




\section{Expediente}

A revista E-Compós é a publicação científica em formato eletrônico da Associação Nacional dos Programas de Pós-Graduação em Comunicação (Compós). Lançada em 2004, tem como principal finalidade difundir a produção acadêmica de pesquisadores da área de Comunicação, inseridos em instituições do Brasil e do exterior.

\section{E-COMPÓS I www.e-compos.org.br I E-ISSN 1808-2599}

Revista da Associação Nacional dos Programas de Pós-Graduação em Comunicação. Brasília, v.21, n.3, set/dez. 2018. A identificação das edições, a partir de 2008, passa a ser volume anual com três números. Indexada por Latindex I www.latindex.unam.mx

\section{CONSELHO EDITORIAL}

Ada Cristina Machado Silveira, Universidade Federal de Santa Maria, Brasi Alda Cristina Silva da Costa, Universidade Federal do Pará, Brasil Alfredo Luiz Paes de Oliveira Suppia, Universidade Estadual de Campinas, Brasil Ana Carolina Rocha Pessôa Temer, Universidade Federal de Goiás, Brasil Ana Regina Barros Rego Leal, Universidade Federal do Piauí, Brasil André Luiz Martins Lemos, Universidade Federal da Bahia, Brasil Angela Cristina Salgueiro Marques, Universidade Federal de Minas Gerais, Brasil Ângela Freire Prysthon, Universidade Federal de Pernambuco, Brasil Anna Cristina Pertierra, Western Sidney University, Austrália Antonio Carlos Hohlfeldt, Pontifícia Universidade Católica do Rio Grande do Sul, Brasi Arthur Ituassu, Pontifícia Universidade Católica do Rio de Janeiro, Brasil Bruno Campanella, Universidade Federal Fluminense, Brasil Bushra Hameedur Rahman, University of the Punjab, Paquistão, Paquistão Cárlida Emerim, Universidade Federal de Santa Catarina, Brasil Carlos Del Valle Rojas, Universidad de La Frontera, Chile Carlos Eduardo Franciscato, Universidade Federal de Sergipe, Brasil Cláudio Novaes Pinto Coelho, Faculdade Cásper Líbero, Brasil Danilo Rothberg, Universidade Estadual Paulista, Brasil Denise Tavares, Universidade Federal Fluminense, Brasil Diógenes Lycarião, Universidade Federal do Ceará, Brasil Dóris Martínez Vizcarrondo, Universidad de Puerto Rico Mayagüez, Porto Rico Eduardo Vicente, Universidade de São Paulo, Brasil

Eliza Bachega Casadei, Escola Superior de Propaganda e Marketing - SP, Brasil Elvira Gomes dos Reis Freitas, Universidade de Cabo Verde, Cabo Verde Eneus Trindade, Universidade de São Paulo, Brasil Erick Felinto de Oliveira, Universidade do Estado do Rio de Janeiro, Brasil Erick Torrico, Universidad Andina Simón Bolívar, Bolívia, Bolívia Erly Vieira Júnior, Universidade Federal do Espírito Santo, Brasil Fabio La Rocca, Université Paul-Valéry Montpellier 3, França Fernando Firmino da Silva, Universidade Federal da Paraíba, Brasil Francisco de Assis, FIAM-FAAM Centro Universitário, Brasil Francisco Elinaldo Teixeira, Universidade Estadual de Campinas, Brasil Francisco Gilson Rebouças Pôrto Junior, Universidade Federal do Tocantins, Brasil Francisco Sierra Caballero, CIESPAL, Equador Frederico de Mello Brandão Tavares, Universidade Federal de Ouro Preto, Brasil Gabriela Reinaldo, Universidade Federal do Ceará, Brasil Germán Rey Beltrán, Universidad Nacional de Colombia, Colômbia Gilson Vieira Monteiro, Universidade Federal do Sul da Bahia, Brasil Gustavo Daudt Fischer, Universidade do Vale do Rio dos Sinos, Brasil Gustavo Hernández Díaz, Universidad Central de Venezuela, Venezuela Heidi Figueroa Sarriera, Universidad de Puerto Rico, Porto Rico Ignacio Aguaded, Universidad Huelva, Espanha Inesita Soares de Araújo, FIOCRUZ, Brasil Itania Maria Mota Gomes, Universidade Federal da Bahia, Brasil Jiani Adriana Bonin, Universidade do Vale do Rio dos Sinos, Brasi João Carlos Ferreira Correia, Universidade da Beira Interior, Portugal Jonathan Cohen, University of Haifa, Israel José Afonso da Silva Junior, Universidade Federal de Pernambuco, Brasil José Luiz Aidar Prado, Pontifícia Universidade Católica de São Paulo, Brasil Josette Maria Monzani, Universidade Federal de São Carlos, Brasil Juçara Gorski Brittes, Universidade Federal de Ouro Preto, Brasil Julián Durazo Hermann, Université du Québec à Montreal, Canadá Juliana Freire Gutmann, Universidade Federal da Bahia, Brasil
Karla Yolanda Covarrubias, Universidad de Colima, México Laura Loguercio Cánepa, Universidade Anhembi Morumbi, Brasil Leonel Azevedo de Aguiar, Pontifícia Universidade Católica do Rio de Janeiro, Brasil Leticia Cantarela Matheus, Universidade do Estado do Rio de Janeiro, Brasil Ling Chen, Hong Kong Baptist University, China Luciana Coutinho Souza, Universidade de Sorocaba, Brasil Marcel Vieira Barreto Silva, Universidade Federal da Paraíba, Brasil Marcia Tondato, Escola Superior de Propaganda e Marketing, Brasil Márcio Souza Gonçalves, Universidade do Estado do Rio de Janeiro, Brasil Maria Ataide Malcher, Universidade Federal do Pará, Brasil Maria das Graças Pinto Coelho, Universidade Federal do Rio Grande do Norte, Brasi Maria Elena Hernández Ramirez, Universidad de Guadalajara, México Maria Elisabete Antonioli, Escola Superior de Propaganda e Marketing - SP, Brasil Maria Teresa Quiroz, Universidad de Lima, Peru Marialva Carlos Barbosa, Universidade Federal do Rio de Janeiro, Brasil Marina Poggi, Universidad Nacional de Quilmes, Argentina Marli Santos, Faculdade Cásper Líbero, Brasil Mateus Yuri Passos, Universidade Metodista de São Paulo, Brasil Mauricio Mario Monteiro, Universidade Anhembi Morumbi, Brasil, Brasil Mayka Castellano, Universidade Federal Fluminense, Brasil Mirta Varela, Universidad de Buenos Aires, Argentina

Mozahir Salomão Bruck, Pontifícia Universidade Católica de Minas Gerais, Brasil Neyla Graciela Pardo Abril, Universidad Nacional de Colombia, Colômbia Nísia Martins Rosario, Universidade Federal do Rio Grande do Sul, Brasil Olga Guedes Bailey, Nottingham Trent University, Reino Unido Paolo Demuru, Universidade Paulista, Brasil

Paolo Peverini, LUISS, Itália

Paško Bilić, Institute for Development and International Relations, Croácia Paula Melani Rocha, Universidade Estadual de Ponta Grossa, Brasil Potiguara Mendes Silveira Jr, Universidade Federal de Juiz de Fora, Brasil Rafael Cardoso Sampaio, Universidade Federal do Paraná, Brasil Rafael Tassi Teixeira, Universidade Tuiuti do Paraná, Brasil Regiane Lucas de Oliveira Garcêz, Universidade Federal de Minas Gerais, Brasil Regiane Regina Ribeiro, Universidade Federal do Paraná, Brasil Renata Pitombo Cidreira, Universidade Federal do Recôncavo da Bahia, Brasil Renato Essenfelder, Escola Superior de Propaganda e Marketing, Brasil Roberto Elísio dos Santos, Universidade Municipal de São Caetano do Sul, Brasil Robson Borges Dias, Universidade Católica de Brasília (UCB), Brasil Rodolfo Rorato Londero, Universidade Estadual de Londrina, Brasil Rosario Sanchéz Vilela, Universidad Católica del Uruguay, Uruguai Roseli Figaro, Universidade de São Paulo, Brasil Saima Saeed, Jamia Millia Islamia, India Sara Brandellero, Leyden University, Holanda Simone Maria Andrade Pereira de Sá, Universidade Federal Fluminense, Brasil Sônia Caldas Pessoa, Universidade Federal de Minas Gerais, Brasil Sun Sun Lim, Singapore University of Technology and Design, Singapura Tatiana Oliveira Siciliano, Pontifícia Universidade Católica do Rio de Janeiro, Brasil Thaïs de Mendonça Jorge, Universidade de Brasília, Brasil Valquiria Michela John, Universidade Federal do Paraná, Brasil Vicky Mayer, Tulane University, Estados Unidos da América do Norte Yamile Haber Guerra, Universidad de Oriente, Cuba 


\section{CONSELHO CIENTÍFICO}

Cristiane Freitas Gutfreind, Pontifícia Universidade Católica do Rio Grande do Sul, Brasil I Eduardo Antonio de Jesus, Universidade Federal de Minas Gerais, Brasil I Eduardo Morettin, Universidade de São Paulo, Brasil I Irene de Araújo Machado, Universidade de São Paulo, Brasil

\section{COMISSÃO EDITORIAL}

Igor Pinto Sacramento, Universidade Federal do Rio de Janeiro, Brasil I Kelly Cristina de Souza Prudencio, Universidade Federal do Paraná, Brasil | Miriam de Souza Rossini, Universidade Federal do Rio Grande do Sul, Brasil

\section{EDITORES ASSOCIADOS}

Rafael Grohmann, Faculdade Cásper Líbero, Brasil I Thaiane Moreira de Oliveira, Universidade Federal Fluminense, Brasil

\section{CONSULTORES AD HOC}

Ada Machado, Universidade Federal de Santa Maria, Brasil | Ana Carolina Escosteguy, Universidade Federal de Santa Maria, Brasil | Andrea França, Pontifícia Universidade Católica do Rio de Janeiro, Brasil | Ariane Holzbach, Universidade Federal Fluminense, Brasil | Benjamim Picado, Birkbeck College, Inglattera | Bruno Souza Leal, Universidade Federal de Minas Gerais, Brasil I Eduardo Morettin, Universidade de São Paulo, Brasil I Felipe Trotta, Universidade Federal Fluminense, Brasil | Francisco Rüdiger, Pontifícia Universidade Católica do Rio Grande do Sul, Brasil | Gislene da Silva, Universidade Federal de Santa Catarina, Brasil | Inês Vitorino, Universidade Federal do Ceará, Brasil I Isaltina Gomes, Universidade Federal de Pernambuco, Brasil I Jairo Ferreira, Universidade do Vale do Rio dos Sinos, Brasil I Karina Janz, Universidade Estadual de Ponta Grossa, Brasil I Kati Caetano, Universidade Tuiuti do Paraná, Brasil I Lilian França, Universidade Federal do Sergipe, Brasil I Liziane Guazina, Universidade de Brasília, Brasil I Márcio de Vasconcellos Serelle, Pontifícia Universidade Católica de Minas Gerais, Brasil I Marta Maia, Universidade Federal de Ouro Preto, Brasil I Maurício de Bragança, Universidade Federal Fluminense, Brasil I Nina Velasco e Cruz, Universidade Federal de Pernambuco, Brasil | Norval Baitello Jr., Pontifícia Universidade Católica de São Paulo, Brasil | Pedro Guimarães, Universidade do Estado do Rio de Janeiro, Brasil | Priscilla Perazzo, Universidade Municipal de São Caetano do Sul, Brasil I Sofia Zanforlin, International Association of Media and Communication Research, Estados Unidos I Talitha Ferraz, Escola Superior de Propaganda e Marketing, Brasil I Tattiana Teixeira, Universidade Federal de Santa Catarina, Brasil I Victa de Carvalho Pereira da Silva, Universidade Federal do Rio de Janeiro, Brasil

\section{EQUIPE DE EDITORAÇÃO}

ASSISTENTE EDITORIAL Marcio Telles | REVISÃO DE TEXTOS Fátima Áli | EDITORAÇÃO ELETRÔNICA Roka Estúdio

\section{COMPÓS I www.compos.org.br}

Associação Nacional dos Programas de Pós-Graduação em Comunicação

Presidente

Marco Roxo

Programa de Pós-Graduação em Comunicação - UFF

marcos-roxo@uol.com.br

Vice-Presidente

Isaltina Gomes

Programa de Pós-Graduação em Comunicação - UFPE

isaltina@gmail.com

Secretária-Geral

Gisela Castro

Programa de Pós-Graduação em Comunicação

e Práticas de Consumo - ESPM

castro.gisela@gmail.com

CONTATO I revistaecompos@gmail.com 